\title{
Ultrasonic Defect Sizing in Grey Cast Iron Compared with Steel, Using the Maximum Echo Amplitude Technique.
}

\author{
Dr. S. I. Ibrahim
}

Mech. Eng. Dept. /College of Engineering /Mosul University Abstract:

In ultrasonic defect sizing using the maximum echo amplitude technique, the reflected echo signal height is taken to be related to the amount of ultrasound propagated energy which is reflected from defects and to the information contained in this reflected energy. In this investigation horizontal drilled holes of known sizes are considered in grey cast iron which is usually treated as the most difficult type of cast irons when ultrasonically inspected, due to its high sound attenuated nature. The defects sizing results obtained from grey cast iron are compared with those obtained from a steel of a similar pearlitic matrix structure as a reference material. 2, 4, $6 \& 8 \mathrm{~mm}$ drilled holes at known depths are prepared in both grey cast iron and steel test samples. Maximum echo amplitude sizing method is adopted, using both compression wave probes $\&$ shear wave probes of $1,2,4 \& 6 \mathrm{MHz}$ frequencies at different scanning positions. Although the results are only limited to defect sizing in grey cast iron with reference to steel, they do

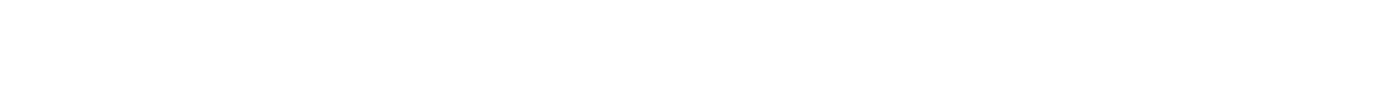

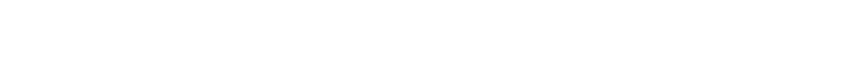

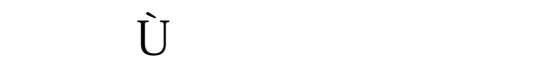

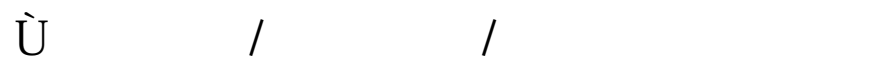

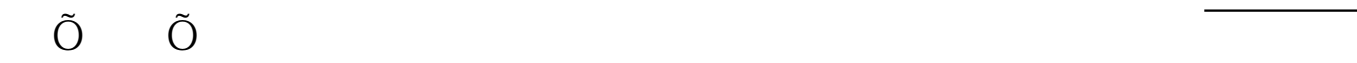

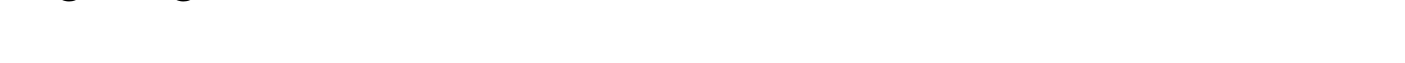

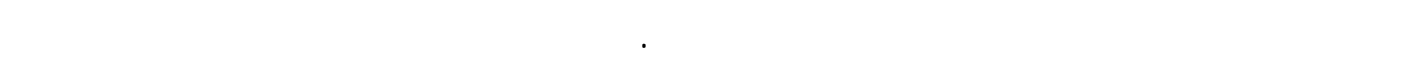

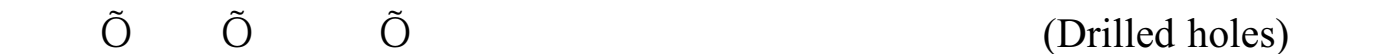

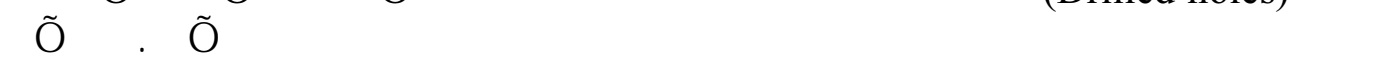

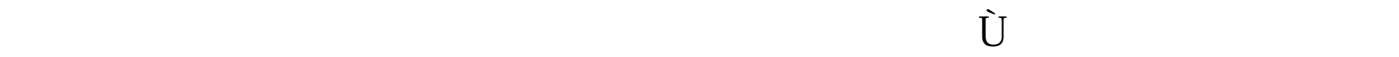

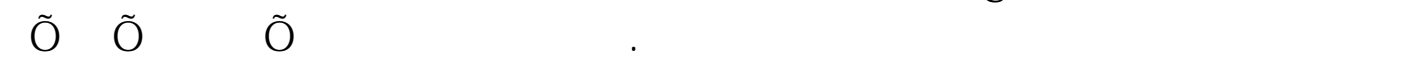

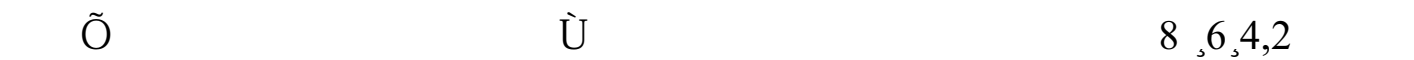

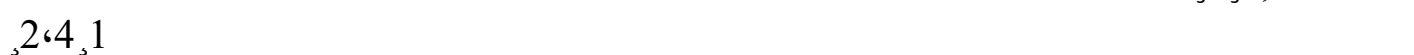

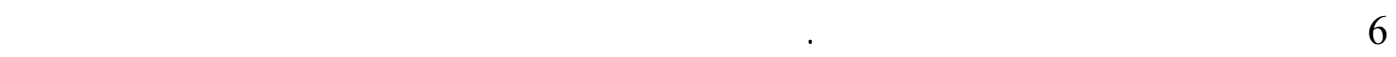

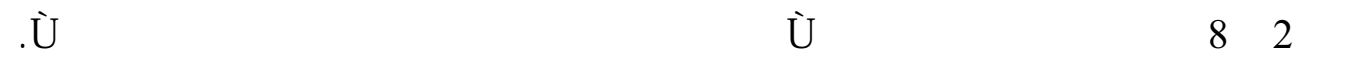

Assistant Prof. of Metallurgy-Teaching, research and consultancy in the fields of metallurgy, NDT, welding, , metallography and allied subjects. Mech. Eng. Dept/ College of Engineering 


\section{Introduction}

Through the years, the majority of ultrasonic applications have been successfully directed towards detection and location of defects in cast \& wrought metal parts, in addition to welded, brazed \& bonded joints. It is now becoming necessary to non-destructively measure such properties as the size, shape \& orientation of defects i.e. defect characterisation [1].

Ultrasonic waves are one of the few forms of energy that can penetrate deep into the material to detect almost any type of defects and make useful estimate of defect size. Further more, these waves are relatively easy to use and has long been known to contain considerable and useful amount of information about the geometry \& nature of defects [1,2]. Unfortunately this valuable inspection technique has been found unsuitable for material such as grey cast iron, which is known to be treated as highly attenuated material to ultrasonic waves due to its heterogeneous structure of composite nature $[3,4]$. i.e. In grey cast iron, the continuity of the metallic matrix is interrupted by infinite discontinuities of the non-metallic matrix component which is the graphite flakes. The graphite flakes having a caustic impedance (acoustic velocity $\times$ density) very much lower than that of the immediate metallic surroundings. As a consequent the graphite develop an interface "micro crack" having strong scattering effect on the ultrasonic wave characteristics, when this takes place, ultrasonic beam may be distorted \& skewed away from the forward direction.[5,6,7] The consequent loss in signal strength (low .echo amplitude response) with high noise level i.e. low signal/noise ratio could lead to possible needless rejection of other-wise acceptable and in some case masking quite high severity defects and restricting wave penetration. $[8,9]$

In view of the complexities out lined above, when ultrasonic inspection of grey cast iron is involved. There is still however, another positive side to the problem, where there is a considerable amount of useful information contained in the reflected signals from defects existing in grey cast iron which could be enhanced, if the right choice of inspection technique is used, i.e. choosing the most effective testing frequency, probe angle (shear wave) \& scanning position.[10] The effectiveness of some of these parameters is experimentally investigated in this article, with a proper interpretation of defects echo signals. This hopefully will assist in yielding some of those structural parameters which have direct influence on grey cast iron ultrasonic inspection in general and defects sizing in particular. 


\section{Materials and Experimental Techniques}

\section{Materials}

The materials involved in this research work, cover both plain-carbon steel and grey cast iron which have been carefully chosen. This is in order to have pearlitic matrix (more than $90 \%$ pearlite), of similar pearlite grain size and pearlite lamination as illustrated in figure9, so that matrix structure influence on ultrasonic wave propagation can be minimised as much as possible or even eliminated. Hence leaving the graphite flakes being the major parameter which will have direct effect on ultrasonic defect sizing in grey cast iron, which is known to be highly attenuated matrix component to ultrasound waves due to the formation of strong reflection interface between graphite flakes and the matrix. Table 1 represents both steel and grey cast iron chemical compositions.

Table 1 Chemical analysis of the materials involved.

\begin{tabular}{|l|cccccccccccc|}
\hline \multirow{2}{*}{ Materials } & \multicolumn{10}{|c|}{ Chemical composition (Weight percent) } \\
\cline { 2 - 12 } & $\mathrm{C}$ & $\mathrm{Si}$ & $\mathrm{Mn}$ & $\mathrm{S}$ & $\mathrm{P}$ & $\mathrm{Ma}$ & $\mathrm{Cr}$ & $\mathrm{Mo}$ & $\mathrm{Ni}$ & $\mathrm{Cu}$ & $\mathrm{V}$ & $\mathrm{Fe}$ \\
\hline Steel & .75 & .30 & .71 & .008 & .01 & --- & .162 & .016 & .081 & .37 & .003 & bal \\
\hline Grey cast iron & 3.6 & 2.0 & .32 & .042 & .03 & --- & --- & --- & --- & --- & --- & bal \\
\hline
\end{tabular}

\section{Test samples preparation}

Two steel test samples and two grey cast iron test samples were machined and ground finished having $90 \times 90 \times 15 \mathrm{~mm}$. dimensions. Four horizontal drilled holes as artificial (simulated) defects of 2, 4, $6 \& 8 \mathrm{~mm}$. diameters were carefully made at certain predetermined depths (locations) as scanning distance of 5, 10, 20 $\& 25 \mathrm{~mm}$. in these test samples as illustrated in figure1. In the case of shear wave or angle probes scanning, the scanning distance depends on the probe angle used i.e. $45^{\circ}, 60^{\circ}$, or $70^{\circ}$ probes, this is shown in figure 2 .

\section{Metallographic Test}

Two suitable size specimens were cut from both steel \& grey cast iron samples for microscopic examination. These specimens were prepared using the usual method of grinding and polishing, then etched by $5 \%$ Nital. The microstructures revealed pearlitic structure of similar grain size and similar pearlitic lamination coarseness with regular distributed medium size graphite flakes (type A) in grey cast iron specimen as shown in figure9, i.e. grey cast iron microstructure is characterised by graphite flakes dispersed through out pearlitic steel like structure. 


\section{Ultrasonic Testing}

\section{Preliminary Test}

The maximum echo amplitude as defects sizing method is well documented, but to assess and evaluate this technique reliability and limitations when grey cast iron is involved, it was decided to carry out a number of preliminary tests. In addition, test sample's shape and dimensions could be established for both compression wave probes scanning and shear wave probes scanning. Suitable testing sensitivity level was also needed (No. of dB required to bring the maximum echo amplitude to a certain height on the oscilloscope screen), and $80 \%$ F.S.H ( Full Screen Height ) was found adequate. This is important at this stage as suitable sensitivity level was necessary as there are a number of testing parameters, such as testing frequency, probe type, probe angle (shear wave), scanning technique and scanning position, which each alone have its own influence.

Two test samples of high carbon steel (pearlitic) and pearlitic grey cast iron of the same rectangular shape \& dimensions were prepared and finished by machine grinding to $20 \times 100 \times 150 \mathrm{~mm}$, dimensions. $2 \mathrm{~mm}$.horizontal drilled holes as the minimum standard reference defects to be adopted were made which are located at the same depth in both samples. The preliminary tests covered both compression and shear wave scanning. From the preliminary results obtained, it was decided that the final testing samples dimensions are to be chosen accordingly as $15 \times 90 \times 90 \mathrm{mms}$. to allow for the $2 \mathrm{~mm}$. defect which is treated as the smallest defect size. $40 \mathrm{~mm}$.scanning distance was found to be the worse scanning distance condition for $2 \mathrm{~mm}$.hole when using $70^{\circ}$ probe and $4 \mathrm{MHz}$ testing frequency.

During this investigation a Kraut Kramer USM2 ultrasonic equipment and probes were used. Index points and probe angle were checked for all angle probes used and calibration was done using the V1-reference block, this is repeated every time probe angle or probe frequency is changed.

All probes were set to obtain the maximum defect echo amplitude height, the amplitude height was taken as the No. of $\mathrm{dB}$ required to bring the maximum defect echo height to $80 \%$ F.S.H . This echo height is taken as being proportional to the reflected energy received from the defect reflecting surface i.e. the maximum echo amplitude sizing technique.

The results obtained are graphically presented as illustrated in figures $3,4,5,6,7, \& 8$ which are to be discussed later.

This investigation can be considered as an attempt to study the feasibility of 
sizing artificial defects of known sizes in the form of horizontal side drilled holes in grey cast iron i.e. detectability and sizing of simulated defects in grey cast iron.

\section{Results and Discussion}

The results obtained through the whole investigation, clearly indicate the difference in behavior between pearlitic steel and pearlitic grey cast iron towards ultrasonics, during simulated (artificial) defects sizing in the form of horizontal drilled holes. Although pearlitic steel is known to be relatively attenuated steel to ultrasound if compared with ferritic type steel. It has been found that high amount of pearlite in the matrix resulted in a higher attenuation of ultrasonic energy. Pearlite with its lameller mixture of ferrite \& cementite could be considered as a discontinuous or inhomogeneous structure within the microscopic range, there upon scattering of sound wave could cause loss of a caustic energy [2]. This should also be true in case of pearlitic grey cast iron under study and sizing defects in less pearlite grey cast iron, should be easier consequently, smaller defects could be located and sized even at a deeper scanning distances.

Steel behavior towards ultrasonic inspection during this study appeared to have no real problem, due to its relatively high echo amplitude and low amplitude attenuation rate. Although ultrasonic testing variables (parameters) such as probe frequency, probe angle (shear), inspection technique i.e. whether compression or shear wave scanning and scanning distance do have there own influence and need to be taken into consideration, but not as serious as in the case of grey cast iron inspection.

The results in grey cast iron clearly demonstrate the direct influence of both testing frequency and scanning distance on defect sizing. Both echo amplitude height and amplitude attenuation are seriously affected by these two parameters. The results in figure 3 and at particularly $6 \mathrm{MHz}$ testing frequency, give clear warning to those involved in locating and sizing small defects ( $2 \mathrm{~mm}$. or smaller) in grey cast iron not to use high frequency probes, specially in grey cast iron castings of more than $20 \mathrm{~mm}$. thick using compression probes. The results of the 6 $\mathrm{MHz}$ frequency probes in figure 3 also illustrate the short depth of penetration limitation of grey cast iron compared with those results obtained in steel.

High echo amplitude and low amplitude attenuation characteristics of the low frequency probes $(2 \mathrm{MHz})$ are clearly indicated in figure 3 for both steel and grey cast iron. This is appeared to be in agreement with the results obtained by Ibrahim [6[ using compression wave probes. In addition the results of figure 3 show that, it is possible to differentiate between various size defects within the size range involved $(2,4,6 \& .8 \mathrm{~mm})$ in both steel and grey cast iron. The results in 
figure 3 also proved that this technique can differentiate between the above defect sizes specially in cast iron where much higher resolution is the characteristic of grey cast iron, at the expense of echo amplitude height losses, if compared with that in steel.

Figure4 demonstrates the possible simple approach to correlate defects size with their relative maximum echo amplitude height in $\mathrm{dB}$. This figure clearly shows how the material factor have direct influence on defect sizing i.e. each material should have its own correlation defects sizing curve with specified testing frequency and scanning distance (casting thickness) other wise miss-leading and unreliable defects size estimation. Figure4 has been constructed for a specific scanning distance i.e. $10 \mathrm{~mm}$ depth.

Figure 5 demonstrates the direct influence of probe frequency on the defect sizing, this is clearly illustrated when small defects are involved.

A series of shear wave probes tests were carried out on sizing horizontal drilled holes 2, 4, $6 \& 8 \mathrm{~mm}$., which have already been sized by compression wave probes.

Their results are presented graphically in figure6. During angle probe (shear) sizing technique, both probe angle and testing frequency were varied with different scanning distance. These results encourage the use of $45^{\circ}$ probe over both the $60^{\circ}$ probes $\& 70^{\circ}$ probes, due to the high echo amplitude response of the 45 probes. This is obviously related to the short scanning distance of these probes which is-clearly shown in the case of grey cast iron results if compared with steel $\mathrm{s}$ results., especially at high testing frequency as shown in figure3.

To study the influence of testing frequency and scanning distance using shear wave probes, $45^{\circ}$ probes with their advantages of high echo amplitude characteristics were used. The results are shown in figure7 these results confirm the need for careful interpretation of the ultrasonic technique factors for reliable defect sizing, i.e. even using the most effective angle probes $\left(45^{\circ}\right.$ probes $)$, the use of high testing frequency needs to be avoided especially when grey cast iron is to be ultrasonically inspected. Casting thickness is an other important factor which requires consideration.

Although the results covered only four drilled hole sizes, i.e. 2,4,6 \& $8 \mathrm{~mm}$, but this investigation could be treated as an assessment of reliability of the maximum echo amplitude as defects sizing method in grey cast iron.

Several investigations [10-19], have been involved in trying to determine those factors which have direct influence on the echo amplitude response, if the 
maximum echo amplitude technique is to be adopted as a reliable defects size estimation method in steels. Their findings confirm that if ultrasonic maximum echo amplitude technique is used, it is possible to detect almost any type of defects and can also make useful estimates of defect size, nevertheless all ultrasonic methods have their own limitations. The quantitative evaluation of defects both by conventional methods or by more sophisticated techniques now under research and development as the accuracy of these techniques depends upon several factors. These factors have been well established and widely documented as for as steels with the exception of those steels having anisotropic nature such as austenitic steels. Heterogeneous materials such as graphite containing cast irons which could be treated as "composite" materials, have been considered as difficult materials to be inspected by ultrasonic, especially grey cast iron. Their response to ultrasonic in general and defects sizing in particular have not been well understood and established.

Early work by the author,[16] clearly illustrated the lower echo amplitude and high amplitude attenuation characteristics of grey cast iron if compared with steel of similar matrix structure, which led to the present investigation. The results obtained confirm the importance of the factors related to ultrasonic technique and to those related to material.

\section{Conclusions:}

From the results obtained, the following conclusions could be justified:

1-Defects size estimation in grey cast iron is possible using the maximum echo amplitude method.

2-Lower defects echo signal amplitude response is the characteristics of grey cast iron compared with steel. Consequently under estimation of. defects size, if the influence of graphite flakes are not taken into consideration.

3-High frequency probes are to be avoided during ultrasonic inspection of grey cast iron, due to their low echo amplitude response and high echo amplitude attenuation i.e. low depth of ultrasonic penetration capability, hence restriction in the inspection of thick section grey cast iron casting.

4-Using this technique, it has been found possible to detect and evaluate 2 tmn.drilled holes (treated as minimum defect size) even at the worse scanning condition using shear probe scanning at $6 \mathrm{MHz}$ testing frequency, provided that grey cast iron casting thickness (scanning distance) is not to exceed the $20 \mathrm{~mm}$ limit.

\section{Acknowledgement}


The author would like to express his thanks and appreciation to the mechanical Engineering Department of Mosul University for the assistance provided to carry out this investigation. Special acknowledgement should go to both Mr. M.L. Dabbo and Mr. M.S. Abidfathi for their efforts in helping to produce this article in its final form.

\section{References}

1-Thompson.R.B, "Overview of ultrasonic NDE research." Non-destructive evaluation of materials, Edited by JJ. Buke and V. Weiss, plenum press New York, 1979, PP.257-280

2-Sziland J AND Scrution.G, "Revealing the grain structure of metals by ultrasonics.”, Ultrasonics, May 1973 ,PP. 114-120.

3-Onozawa. M, Katmine. A, Isch,I.Y and Ohirm,G., "Ultrasonic testing of near surface flaws in castings." British J of NDT, Vol.31, No.11, Nov.1989, pp.611-615

4-Prasad.R, "Recent ultrasonic techniques for quality evaluation of castings." British J.ofNDT.,Vol.31,No.4, Sept.1989 PP.484-486.

5-Rose.J.L and Tverdokhlebor.A, "Ultrasonic testing consideration for metals with mild anisotropy.”, British J.ofNDT.,Vol.3 1, No.2,Feb 1 989,PP.7 1-76.

6-Magistral.G, Rostaldo,A and Tognarini.A, "An acoustic technique for the non destructive evaluation of small ductile iron castings by drop-impact excitation.” British J.of NDT, Vol.27, No.2,March 1985, PP.75-82.

7-Smith.P.L \& Perring.S, "A comparison of the ultrasonic attenuation of Fe-C alloys in annealed, normalised and quenched states." AERE.R1 0956, Harwell, Aug.1983,PP.1-12.

8-Granville. R.K. \& Tayler.J.L, "High noise level during the ultrasonic testing of Titanium alloys.” British J.of NDT,Vol.27, No.3, May 1985, PP.156-158.

9-Lee.S.C and Suen.J.M, "Ultrasonic non-destructive evaluation of matrix structure and modularity in cast irons." Metallurgical Trans. A, Vol.20 A, Nov. 1989,PP.2399 2407.

10-Rogerson.A and Margatroyd.R.A, "Defects characterisation using ultrasonic techniques" Research techniques in NDT ,Edited by R.S. Sharpe, Vol.4, Academic Press, London, 1980

11-Ibrahim. S.I \& Whittaker V.N, "The influence of compressive stresses and other factors on the detection of fatigue cracks using ultrasonics" British J.of NDT.Vol 22 ,No.6 Nov.1980,PP.286-290

12-Howl.D.A, "The correlation of defect size and reflected ultrasonic signal in extruded bar stock", Ultrasonics, 1984, PP.186-192

13-Ibrahim.S.I and IJbrahim.T.K,"The influence of heat-treatments on the ultrasonic defect size estimation in carbon steel using shear wave probes." 
Eng. \& Technology Journal, Iraq, Vol.12, No.11,1993 PP 29-39

14-Whittle.N.J, “Advances in ultrasonic flaw detection.”, C.E.G.B Research, Nov. 1979,PP.33-44

15-"Ultrasonic techniques for quantitative evaluation of weld defects and their limitations.", Doc. 11s/1lw-675-81,Prepared by Commission V of the $11 \mathrm{w}$, welding in the world, Vol.19,No.Y2,1981 PP.7-11

16-Ibrahim.S.I., and Ahmad. M.S, "Ultrasonic inspection of cast iron using the maximum echo amplitude technique." 2nd Jordanian International Conference of MecEEng.flMEC. ,PP.1 126-1132.

17-Silk..M.G., "Estimates of magnitude of some of the basic source of error in ultrasonic defect sizing." AERE-R9023,1978

18-Yacoub ,K.A and klidhir, A.H., "Detection of explosive welding interface effect on the ultrasonic echo-amplitude response.", AL Rafidain Eng.g.Joumal ,Iraq ,vol. 10,No.2,2002,pp.70-79.

19-Khidhir, A.H., "Ultrasonic investigation of effect of deformation and heattreatment of steel, using the pulse-echo technique 'JMIEC99' Jordan, 9-12 May 1999, pp.557-569 


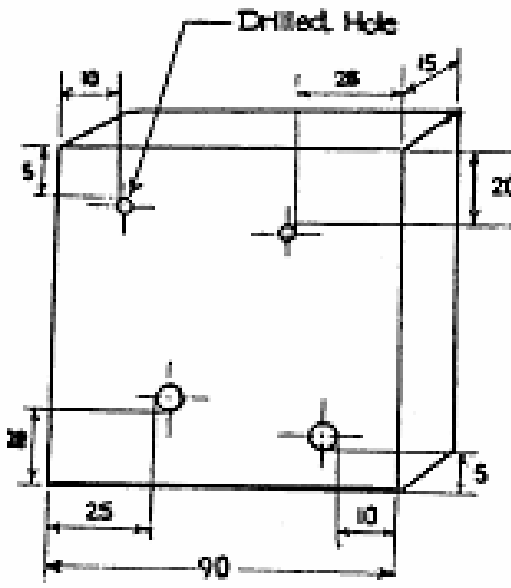

a. $z$ \& $4 \mathrm{~mm}$ drilled holes

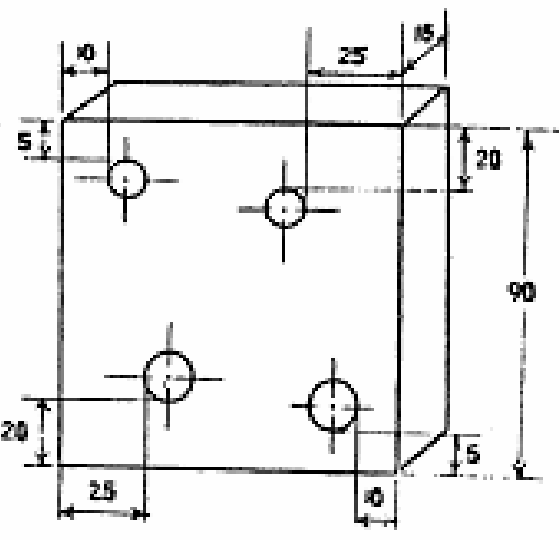

b. 6 \& $8 \mathrm{~mm}$ drilled toles

Fig_(1) Test samples shape and dimensions with drilled holes and their locations (all dimensions in mms)

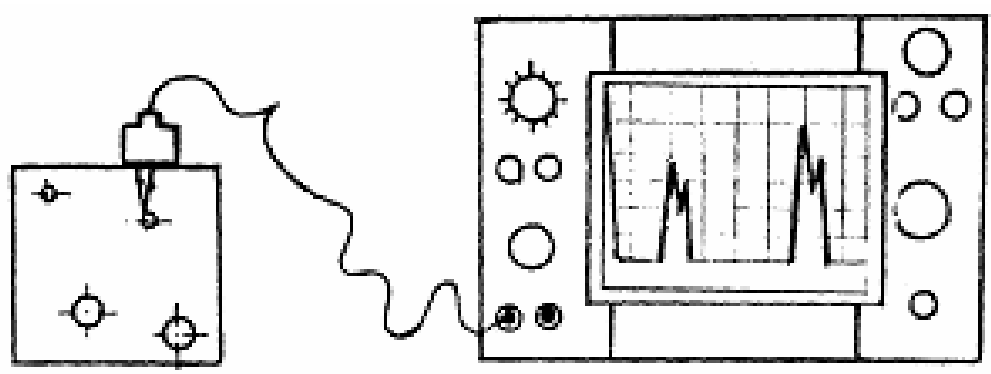

a. Normat probe searning

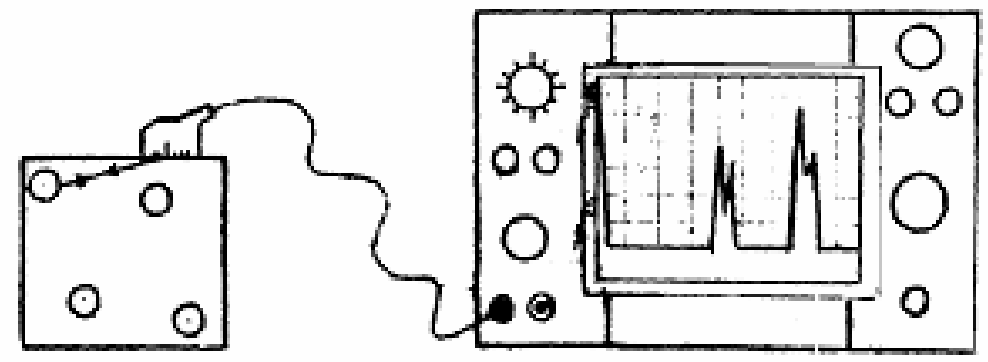

b. Angle probe scanning

Fig.(2) (a,b) Typical normal and angle wave probe scanning at $1 / 2$ skip for maximum echo height from side drilled hole, showing construction and mode of operation 


\section{$\begin{array}{llll}\text { Al_Rafidain engineering } & \text { Vol.13 } & \text { No.2 } & 2005\end{array}$}

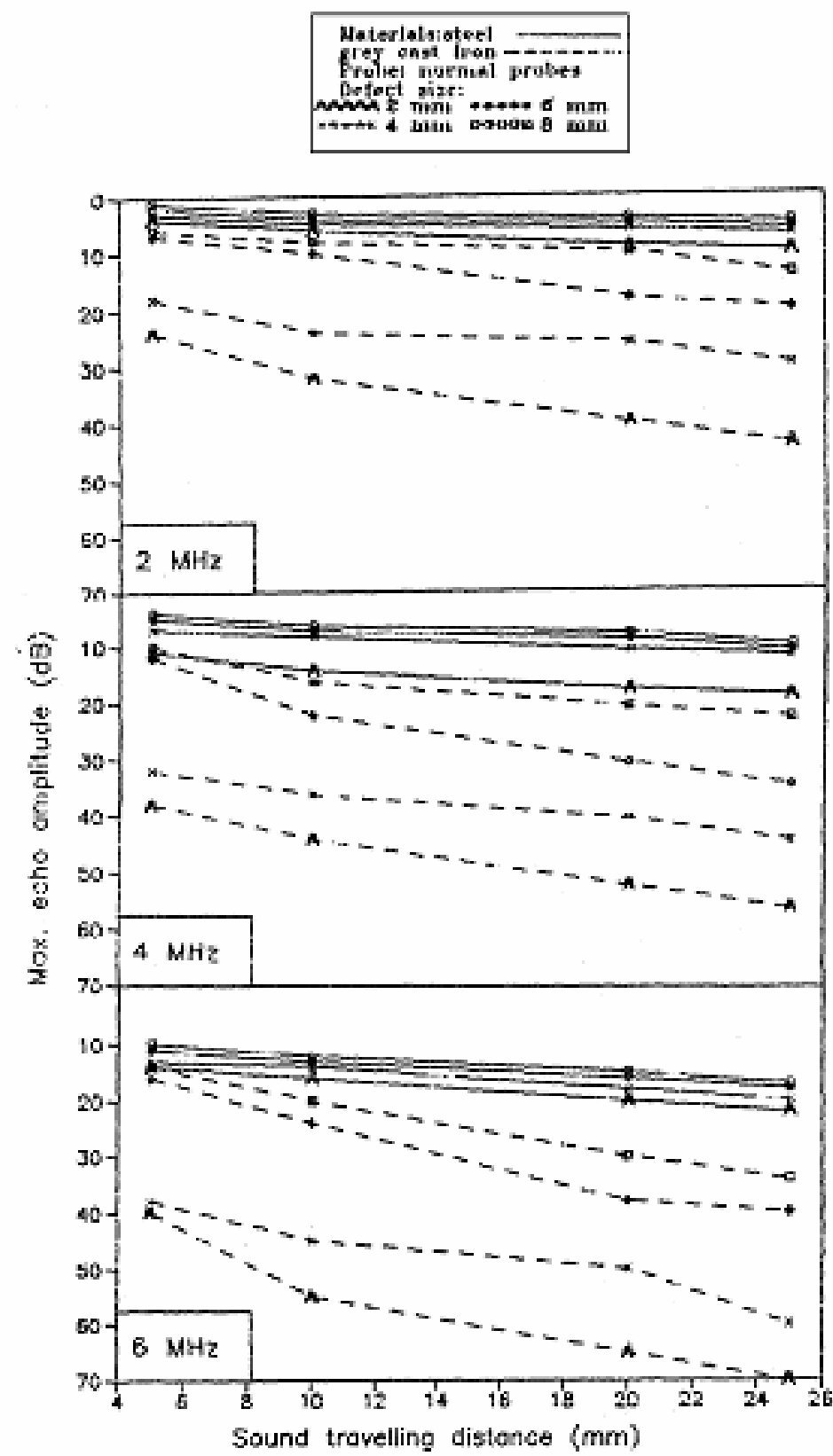

Fig,(3) The influence of sound trave lling distance on defect sizing in steel \& grey cast iron using $2 \mathrm{MHz}, 4 \mathrm{MIIx}$ \& $5 \mathrm{MHz}$ frequancies normal prohes 


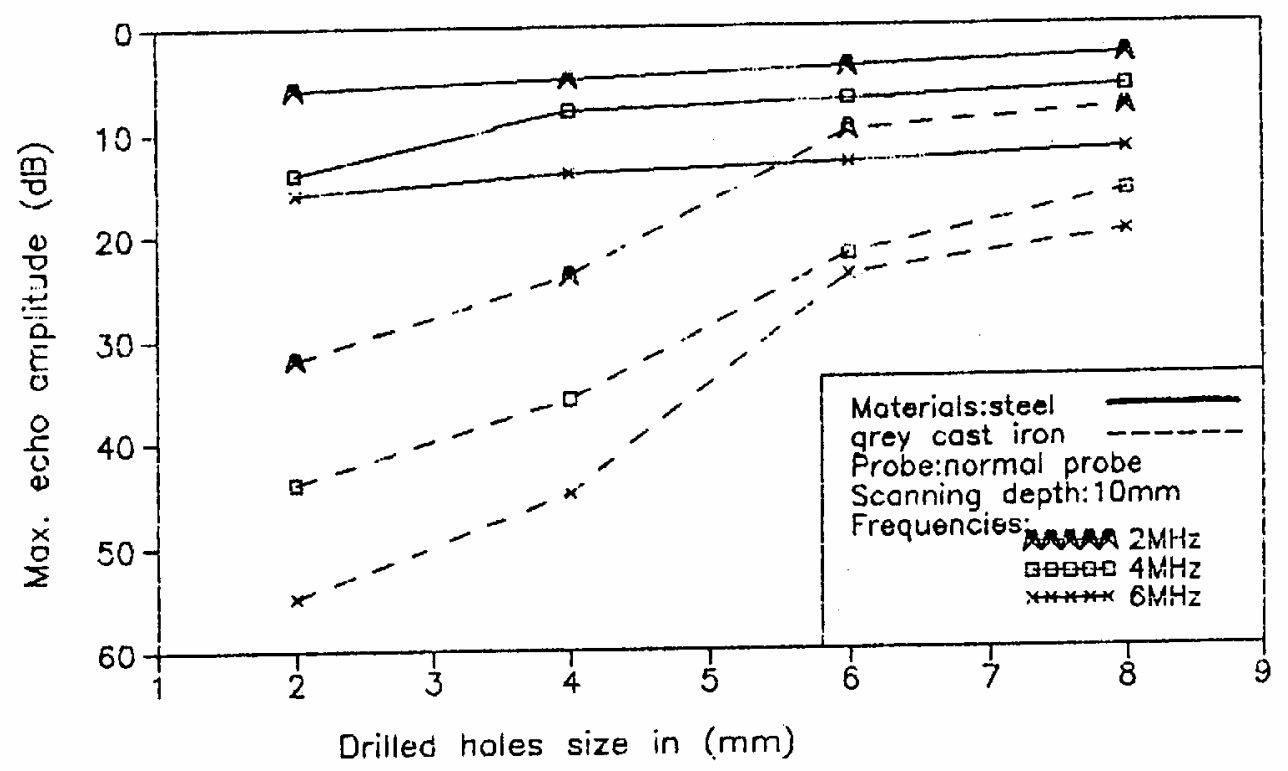

Fig.(4) Correlation between defect size and the ceho amplitude in steel \& grey cast-iron using normal probes of different frequencies at scanning distance of $10 \mathrm{~mm}$ depth

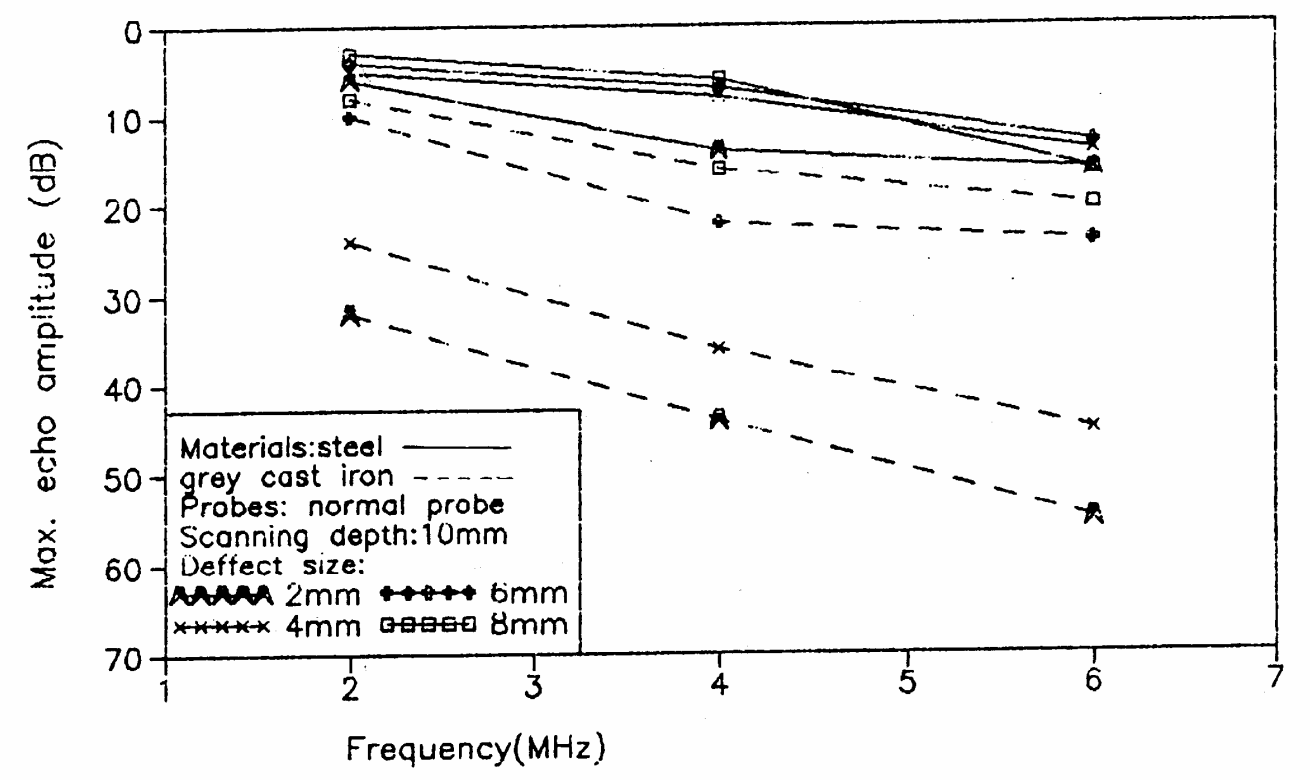

Fig. (5) Effect of frequency on the defect sizing in both steel \& grey cast iron using normal proes at $10 \mathrm{~mm}$ depth scanning distance. 


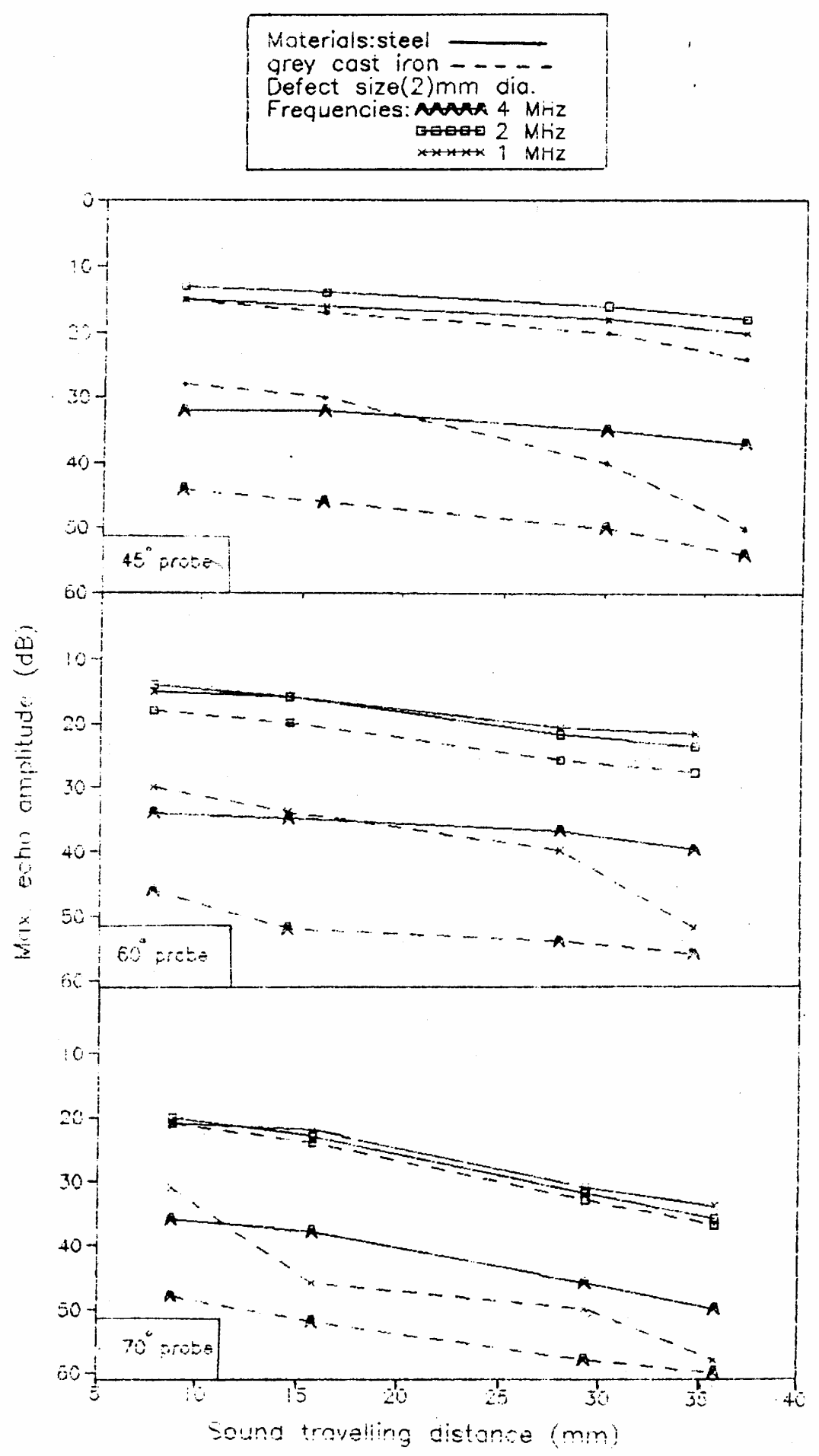

Fig. (6) The influence of both testing frequency $\&$ scanning position during ultrasonic defect sizing in steel $\&$ grey cast iron using $45^{\circ} 60^{\circ} \& 70^{\circ}$ angle probes 


\section{$\begin{array}{llll}\text { Al_Rafidain engineering } & \text { Vol.13 } & \text { No.2 } & 2005\end{array}$}

Wicterigis stes:

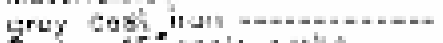

Frotes:45 yigite protes

Seorfing Eistonce:

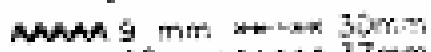

areas $16 \mathrm{~mm}+\phi+4+37 \mathrm{~mm}$

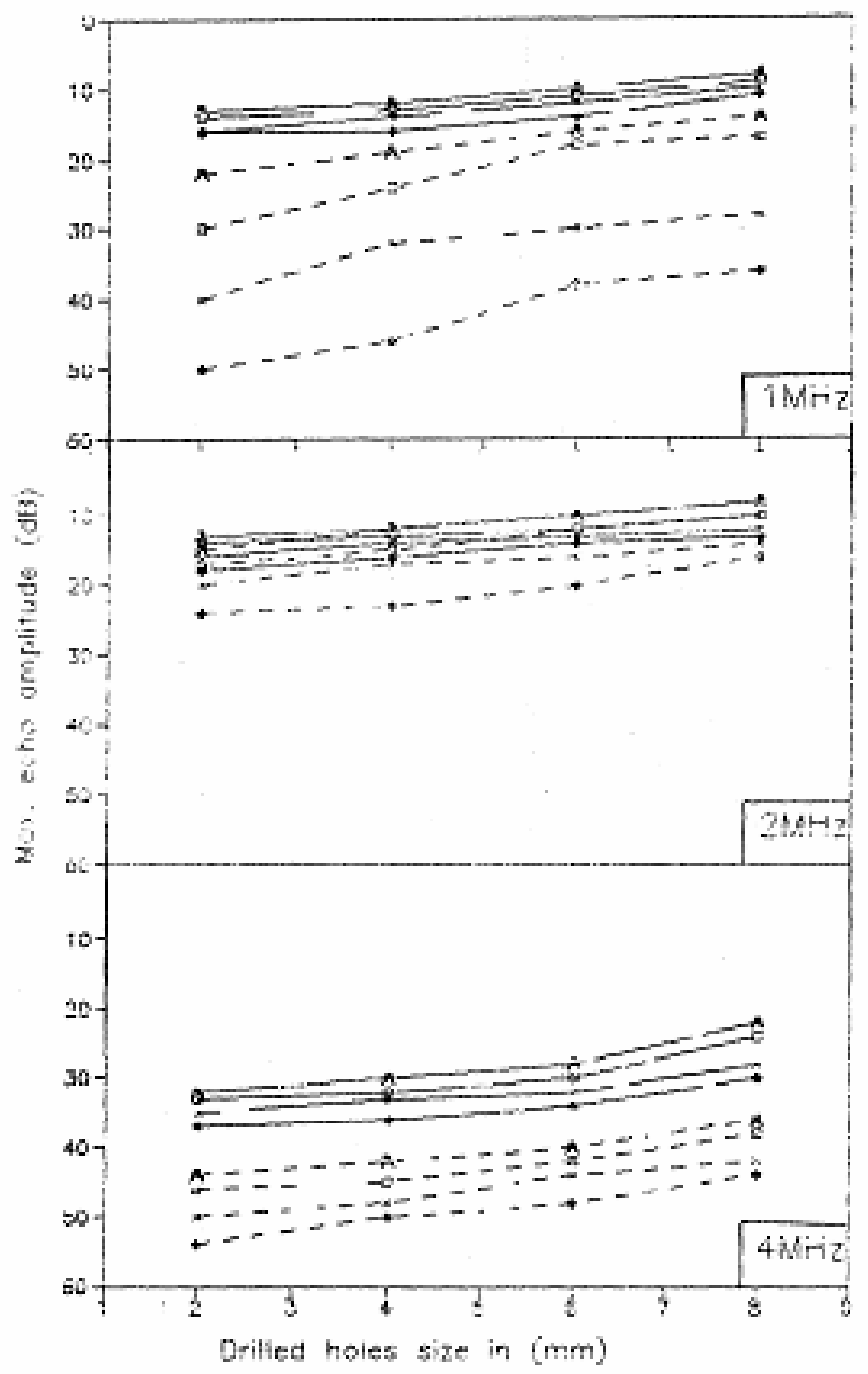

Fig, (7) Comparison between ultrasonic defect sizing in steel \& grey cast iron at various scanning positions and $1 \mathrm{MHz}, 2 \mathrm{MHz} \& 4 \mathrm{MHz}$ testing frequencies using $45^{\circ}$ angle probes. 


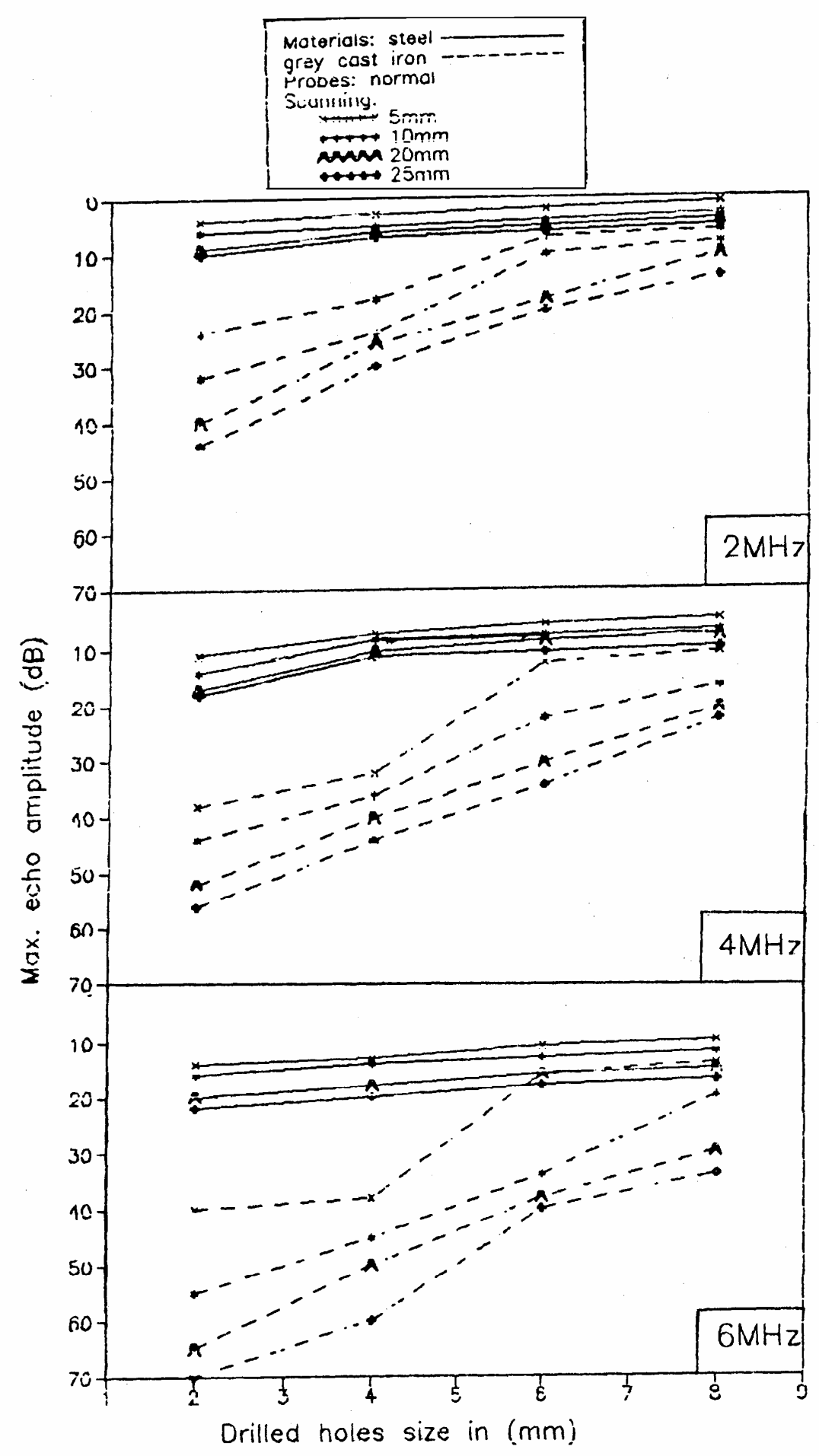

Fig. (8) Comparison between ultrasonic defect sizing in steel \& grey cast iron at various scanning position $\&$ different frequencies using normal propes 
$\begin{array}{llll}\text { Al_Rafidain engineering } & \text { Vol.13 } & \text { No.2 } & 2005\end{array}$

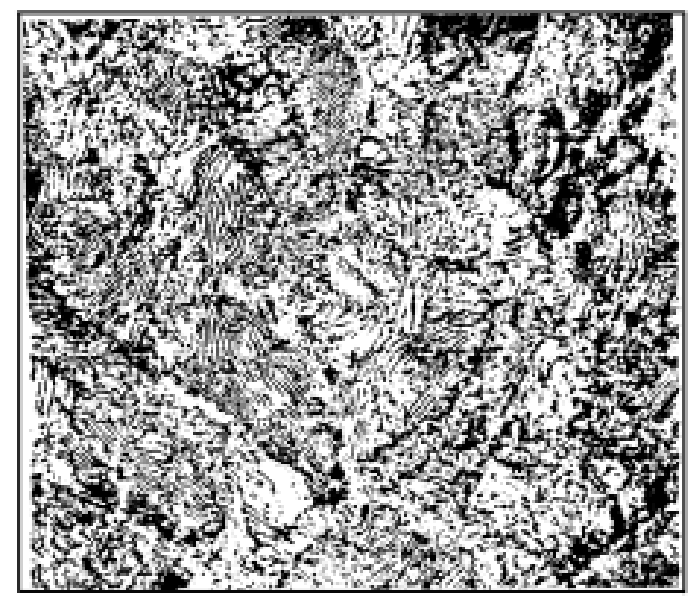

(a)

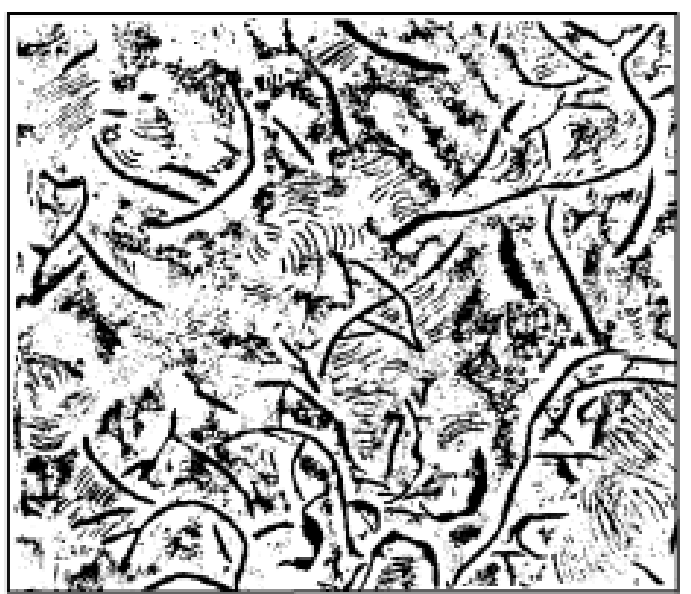

(b)

Fig.9 Photomicrographs showing:

(a) pearlitic plain carbon steel (X300)

(b) pearlitic grey cast iron $\quad(\mathbf{X} 300)$ 